\title{
O CONSUMO DE MASSA: A OBSOLESCÊNCIA PROGRAMADA NA SOCIEDADE CONTEMPORÂNEA
}

\author{
Edinaldo Enoque Silva Junior* \\ Paulino Eidt**
}

\begin{abstract}
Resumo
Este artigo, de cunho teórico, teve como objetivo compreender as transformações societais oriundas da sociedade de consumo - como o mundo se aglutina por meio dos avanços tecnológicos, da homogeneização da cultura baseada no consumo de massa e dos processos de verticalização proveniente dos que consomem e dos que não podem mas querem consumir. Num segundo momento, teve-se como propósito analisar os diferentes padrões de consumo vivenciados no Extremo Oeste de Santa Catarina a partir da primeira metade do século XX. Trata-se de uma análise feita a partir da implantação da propriedade privada na região por descendentes europeus. A região se adaptou a dois períodos distintos: teve, no seu início, poucos parâmetros externos, tendo em vista seu isolamento pela falta de meios de comunicação e de transportes - este período se estendeu até por volta da década de 1970; e, pós-70, quando as grandes agroindústrias (leite, aves e suínos) colocaram-se como centrais irradiadoras da modernidade da região, governando de acordo com suas leis do mercado.
\end{abstract}

Palavras-chave: Subsistência. Sociedade de consumo. Globalização.

*Graduado em História, especialista em Ciências Sociais pela Universidade do Oeste de Santa Catarina (Unoesc). E-mail: <enqouesmo@hotmail.com>.

** Doutor em Ciências Sociais pela PUC-SP, professor da Rede Pública de Ensino de Santa Catarina e do Programa de Mestrado em Educação da Universidade do Oeste de Santa Catarina (Unoesc). E-mail: < paulino.eidt@ unoesc.edu.br>. 


\section{Introdução}

Um mercado avassalador dito global é apresentado como capaz de homogeneizar o planeta quando, na verdade, as diferenças locais são aprofundadas. Há uma busca de uniformidade, ao serviço dos atores hegemônicos, mas o mundo se torna menos unido, tornando mais distante o sonho de uma cidadania verdadeiramente universal. Enquanto isso, o culto ao consumo é estimulado. (SANTOS, 2001, p. 19).

Há 200 milhões de anos existiu, segundo os geólogos, um único continente, denominado Pangeia. "Pangeia" originase do grego pan (junto, inteiro) e geia ou gaia, deusa grega que personifica a terra e todos seus elementos.

Pangeia seria o conjunto dos continentes de maneira física, efetivamente colados uns aos outros, formando um todo, coeso, unido, global. Durante a evolução planetária, a pangeia foi sendo substituída por continentes menores, isolados como a Oceania, ou ligados por estreitas faixas de terra, como as massas hoje compreendidas por América do Norte e América do Sul, que são ligadas pela América Central, ou o Oriente Médio e a África, unidos pelos territórios hoje correspondentes a Israel e Palestina. Entretanto, no decorrer dos séculos, o todo inteiro do Pan dissolveu-se graças às Placas Tectônicas - placas flutuantes sobre o magma quente do interior da terra, que se moveram lentamente e movem-se ainda hoje. Para esse processo de desprendimento do continente, criou-se a teoria da Deriva Continental.

Hoje, século XXI da Era Cristã, é possível utilizar alguns desses conceitos para compreender o mundo e suas transformações. Em linhas gerais, podemos classificar o mundo contemporâneo como a Neopangeia, e a Deriva Continental substitui-se pela Deriva Humana.

Como Lindo (2000, p. 79) observa: "Estamos vivendo uma série de mutações, tanto nas relações sociais como nas estruturas materiais, tanto nas individualidades humanas como no curso da evolução da vida em geral.” Nos últimos 70 anos, principalmente após a Segunda Grande Guerra, o mundo se viu ligar novamente. Essa ligação, como sabemos, não se deu de forma física como a pangeia, mas econômica, virtual e técnica. A esse nome consentiu-se chamar de globalização. E globalização leva a uma ideia muita mais economicista do que qualquer outra coisa, como explica Lindo (2000, p. 125): "Falou-se tanto 
na 'globalização' nos últimos anos, que acabamos por dar-nos conta de que esse conceito explica muito pouco e encerra muitas contradições." Por ora, a metáfora da neopangeia visa abranger a ligação geral dos continentes não apenas em termos econômicos, mas sociais, pessoais e informacionais, de valores éticos, estéticos, entre outros.

A Deriva Humana ganha vulto com o processo de esfacelamento dos pressupostos éticos e morais quando os fins passam a justificar os meios. Os fins justificam os meios no mundo moderno pelo simples fato de não ser mais possível antever qualquer certeza nos dias e semanas vindouras, que dirá em meses ou anos. $\mathrm{O}$ exemplo da crise nas impenetráveis ditaduras mulçumanas dão mostras disso. Tsunamis avassaladores destroem o Japão, e um perigo atômico repentino assombra novamente o mundo. $\mathrm{O}$ indivíduo contemporâneo incerto e confuso pela velocidade constante e frenética se rende às fobias e ansiedades. $\mathrm{E}$ as ideologias do mercado global unido pelos sinais invisíveis da neopangeia mostram saídas e soluções no consumo de massa:

O mesmo sistema ideológico que justifica o processo de globalização, ajudando a considerá-lo o único caminho histórico, acaba, também, por impor uma certa visão da crise e a aceitação dos remédios sugeridos. Em virtude disso, todos os países, lugares e pessoas passam a se comportar, isto é, a organizar sua ação, como se tal "crise" fosse a mesma para todos e como se a recita para afastála devesse ser geralmente a mesma. $\mathrm{Na}$ verdade, porém, a única crise que os responsáveis desejam afastar é a crise financeira e não qualquer outra. Aí está, na verdade, uma causa para mais aprofundamento da crise real - econômica, social, política, moral - que caracteriza o nosso tempo. (FARIA, 1991, p. 52).

A neopangeia só é possível por meio da comunicação. Sem a Internet, a TV aberta e a cabo, os sinais de celulares e demais aparelhos de localização e comunicação, não seria possível a reunificação planetária. Para Moraes (1997, p. 76), "Os meios de comunicação de massa multiplicaram-se e diversificaramse criando um sistema mundial de multirredes e multicanais, provocando ao mesmo tempo efeitos de homogeneização e de desestruturação cultural em todas as sociedades." O mundo "ligase" de uma forma surpreendente e esmagadora. $\mathrm{Na}$ neopangeia, o mundo está ligado como nunca esteve antes. Entretanto, 
ligado não quer dizer unido, pois a Deriva Humana tem levado os indivíduos a isolarem-se de modo assustador. Entretanto, as placas movem-se e o mercado global causa sempre terremotos e tsunamis para mover a massa à deriva e desligada da neopangeia.

A Deriva Humana é abalada pelas placas tectônicas da neopangeia quando, por algum motivo especial, o mercado cria mecanismos de aglutinação e frenesi entre os habitantes do mundo. Os tubos e condutos da comunicação levam aos indivíduos da neopangeia vontades e inserem em seus corações desejos. E o grande segredo de tal processo está na oferta publicitária. Segundo Moraes (1997, p. 25),

Os aparatos de divulgação disponibilizam signos sociais que assumem significação mundial. Não apenas de marcas [...] como também de referências culturais [...] afirmam-se perante os consumidores, sem procedências nitidamente identificadas. Tais signos prefiguram uma memória coletiva partilhada por pessoas dispersas nos rincões geográficos. Não mais uma memória enraizada em tradições nacionais, regionais ou locais, mas traçada e reconhecível em estilos de vidas universais.

É no consumo que os indivíduos contemporâneos se identificam; entretanto, essa identificação tem fim marcado, tornando impossível uma relação duradoura entre homens e mulheres, pois os produtos fabricados pelos mercados móveis e fluidos da contemporaneidade têm como característica máxima a obsolescência programada. Os produtos têm nas placas fluidas do mercado data e hora para seu fim, e será exatamente no momento do próximo lançamento, da próxima estação ou do próximo desfile. Segundo Morin (2005, p. 112), “Os comunicadores sociais, o show business e as "indústrias culturais" aparecem como um novo poder que se manifesta na formação da opinião pública, no consumo e nos padrões do comportamento coletivo e de seu fim eminente".

\section{O descartável e o efêmero}

A obsolescência programada lança mão de um mecanismo importante para a compreensão da neopangeia - esse mecanismo é o desejo. Os laços se tornam virtuais, a ânsia de estimular o consumo transforma as propagandas em apelos fetichistas e sexistas, levando o indivíduo contemporâneo a uma espécie de sonambulismo, o fazendo confundir sonho e realidade. O homem 
isolado, ansioso para saciar seus desejos de consumo que já se misturam com desejos da libido, se torna alvo fácil dos sistemas escorregadios do mercado. Para Bauman (2010, p. 43),

A cultura de hoje é feita de ofertas, não de normas. A cultura vive de sedução, não de regulamentação; de relações públicas, não de controle policial; da criação de novas necessidades/desejos/exigências, não de coerção. Esta nossa sociedade é uma sociedade de consumidores. $\mathrm{E}$ como o resto do mundo visto e vivido pelos consumidores, a cultura também se transforma num armazém de produtos destinados ao consumo, cada qual concorrendo com os outros para conquistar a atenção inconstante/errante dos potenciais consumidores, na esperança de atraí-la e conservá-la por pouco mais de um breve segundo.

A metáfora da neopangeia enquadra-se no entendimento do homem contemporâneo. Sabemos que estamos mais ligados do que nunca por cabos de internet, sinais de satélite, conexões aéreas e imagens da TV e do cinema; em contrapartida, encontramos em explicações de cientistas sociais como Birman (1999, p. 97), por exemplo, uma sociedade de homens e mulheres solitários, vazios de contato humano e ansiosos por preenchimentos afetivos, inconclusos e sem amparo:

O problema de uma cultura de individualismo intenso é que ela acaba destituída de comunidade. Uma comunidade não se forma sempre que as pessoas interagem umas com as outras; as verdadeiras comunidades são unidas pelos valores, normas e experiências comuns aos seus membros. Quanto mais esses valores comuns estiverem arraigados, maior o senso de comunidade. Entretanto, para muitas pessoas a troca entre liberdade pessoal e comunidade não parece óbvia ou necessária. À medida que as pessoas eram liberadas de seus laços tradicionais com cônjuges, famílias, vizinhos, locais de trabalho ou igrejas, elas pensavam que poderiam ter ao mesmo tempo conexões sociais que elas mesmas escolheriam.

O processo de esfacelamento do local, provocado pelas informações em rede e pelos meios de comunicação de massa, tende a transformar a COMUNidade em sociedade. Aquilo que era comum num grupo específico de pessoas localmente agrupadas passa a ser modificado por ideias globalmente sugeridas pelos anúncios e programas de TV.

Desse modo, a comunidade tende a fragilizar-se com o ímpeto massivo do externo e o local se transforma em social 
onde as pessoas vivem mas não convivem, onde os gostos estão em outra parte, onde a reunião de fim de tarde é substituída pelo episódio da novela, onde a conversa familiar e substituída pela concentração e silêncio que requer o filme:

[...] as massas populares urbanas e de uma parte dos campos têm acesso a novos padrões de vida: entram progressivamente no universo do bem-estar, do lazer, do consumo, que era até então o das classes burguesas. As transformações quantitativas (elevação do poder aquisitivo, substituição crescente do trabalho da máquina pelo esforço humano, aumento do tempo de lazer) operam uma lenta metamorfose qualitativa: os problemas da vida individual, privada, os problemas da realização de uma vida pessoal se colocam, de hoje em diante, com insistência, não mais apenas no nível das classes burguesas, mas da nova camada salarial em desenvolvimento. (GASSET, 2002, p. 89).

O processo de liquefação do local e sua inserção nos mercados mundiais destituem gradual e paulatinamente a originalidade pertinente a grupos locais. $\mathrm{O}$ caldo orgânico que surge com a neopangeia tende a homogeneizar os povos, maneiras, costumes e práticas comunitárias. É comum vermos na TV ou na Internet povos antiamericanos do Oriente Médio e da Ásia usando Nike e fumando Marlboro, por exemplo. Isso explicita que o consumo e o status falam mais alto que desavenças religiosas e culturais.

A máquina maquina o consumidor. A estetização e a estilização promovem a diferenciação contínua e inadequada daquele que não busca diferenciação social. Entretanto, pela busca e pelo incentivo desenfreado de diferenciação, diferenciação essa sugerida pelos anúncios de carros, de shampoo, de perfumes, de refrigerantes, tornamo-nos uma turbe de diferentes-iguais, pois as falas, os gestos, os maneirismos, as roupas que prometem diferenciar igualam, e excluem, pois nem todos podem, ou querem, ser "diferentes". Nesse processo, como explica Bauman, a própria cultura é oferecida como produto e consumida com profusão por homens e mulheres do mundo todo.

Se o mundo habitado por consumidores se transformou num grande maganize onde se vende "tudo aquilo de que você precisa e com que pode sonhar", a cultura parece ter se transformado atualmente em mais um de seus departamentos. Como nos outros, suas prateleiras estão lotadas de mercadorias renovadas diariamente, e as caixas são decoradas com anúncios de novas ofertas destinadas 
a desaparecer depressa, como as mercadorias que anunciam. Tanto

as mercadorias quanto os anúncios publicitários são pensados para suscitar desejos e fisgar vontades para impacto Maximo da obsolescência programada. (BAUMAN, 2010, p. 32).

Entretanto, o mercado sob a égide da obsolescência programada gira a roda da fortuna e torna esses diferentes ultrapassados e a corrida pela diferenciação é novamente iniciada, e assim será ad infinitum, porque as placas tectônicas do mercado global flutuam livremente sobre novos pés e não temos como ou não queremos pará-la. Anestesiados assistimos, como o personagem do filme Laranja Mecânica, que, preso a uma cadeira e com os olhos presos para ficar bem abertos, passava horas em frente à televisão sendo impregnado de milhões de anúncios e notícias sem nada poder fazer. A única função da obsolescência programada é tornar sem função as mercadorias pelo mercado oferecidas. Logo, a programação da obsolescência equivale ao tempo exato do descarte do novo eterno, eterno enquanto dure.

\section{Dos grandes centros ao interior: o processo de desintegração comunal}

Observa-se com maior frequência o interior das cidades serem invadidos por outdoors. Os últimos lançamentos estão, mais do que nunca, presentes nos possíveis últimos redutos comunitários. Lançamentos de carros demoram em torno de cinco a dez meses para serem entregues devido à quantidade de pedidos. Lançamentos do São Paulo Fashion Week e de outros desfiles de moda espalhados pelo mundo estão nas vitrines dessas cidades em questão de dias. Os modelos de casas e interiores apresentados em revistas especializadas têm transformado as cidades pequenas em algo similar aos grandes centros urbanos, inclusive com a construção de condomínios fechados e segurança vinte e quatro horas, mesmo sendo o índice de homicídios e outros crimes baixíssimo.

O que não surpreende, pois todos sabem que até os objetos de desejo logo envelhecem, perdem o brilho num segundo. Os editores das revistas de luxo sempre são capazes de tomar pulso da situação; junto com as informações sobre as novas coisas que você "tem que fazer" e "tem que ter", suprem seus leitores, de maneira regular, com conselhos sobre "o que está out" e deve ser descartado. (MORAES, 1997, p. 15). 
A relação consumo, estilo e estética é imprescindível para a manutenção da obsolescência programada e para a expansão do desejo. É preciso mudar o gosto das pessoas com muita frequência para as placas do capitalismo continuarem deslizando. Alguns terremotos acontecem, como a crise do consumo de 2010, entretanto, mecanismos são criados para sanar problemas desse tipo, ou seja, com mais consumo.

No mundo do consumo desenfreado, os jovens são alvos fáceis. Empresas se especializam em como atingir os desejos dos jovens e, com isso, atingir dividendos astronômicos a partir do consumo deles advindo. Mas é interessante notar que os pais são tão enfeitiçados quanto os filhos. O sistema criou nos corações de pais e mães o dever e a obrigação de serem eternos jovens. Logo, isso se torna um mascaramento: pais compram para os filhos, e depois compram para si próprios para se parecerem com estes. Em andanças aleatórias, observamos crianças entre dez e doze anos que usavam tênis da marca Nike, All Star, Ecko, Coca-Cola, sem contar os bonés, calças, camisas e cadernos de grifes famosas.

Segundo Nietzsche (2007,p.16), "Aquilo que se faz por amor está sempre além do bem e do mal." Por amor os pais enchem seus filhos de modas e modismo para sanar as suas próprias. Por amor pais e mães não medem as consequências e lançam seus filhos no mundo do consumo, tornando-os perfeitos consumidores. Por amor os pais atendem os desejos dos filhos e os pedidos das grandes corporações industriais. $\mathrm{O}$ que fazer se os próprios pais estão anestesiados pela deslumbrante equação do comprardescartar-comprar?

A alegria de "livrar-se" de algo, o ato de descartar e jogar no lixo, esta é a verdadeira paixão do nosso mundo. A capacidade de durar não joga mais a favor das coisas. Dos objetos e dos laços, exige-se apenas que sirvam durante algum tempo e que possam ser destruídos ou descartados de alguma forma quando se tornarem obsoletos - o que acontecerá forçosamente. (IANNI, 2007, p. 33).

Marx (2009, p. 41) anunciou: "proletários do mundo, univos”. Letra morta. Não existe mais proletário, isso é fato. O que existe são burgueses em potencial. Não há mais luta de classe, e a luta pela transformação, repartição e igualdade proposta pela utopia marxiana, entre tantas outras, sucumbiu ao mercado. $\mathrm{O}$ que há é a competição por distinção. Ricos lutam para continuar se distinguindo da classe média cada vez mais numerosa e ávida 
por novidades. Por seu turno, a classe média luta para alcançar a

sofisticação dos ricos e distinção entre si. $\mathrm{Na}$ base do processo, encontramos os pobres, que, mesmo sem as condições básicas de saúde, ensino e moradia, pelas quais deveriam lutar, encontram na falsificação, nos produtos da estação passada e nas grandes queimas de estoque a distinção para com os seus.

A neopangeia dá mostras claras de uma vida estetizada e estilizada; e a ética e a COMUNicação dão mostras claras de ocaso. A neopangeia, com suas placas flutuantes do mercado global, levou homens e mulheres para deriva. Restam os redutos interioranos como fonte de inspiração para aqueles que veem no consumismo um mau presságio. No que tange à relação dos humanos para com o outro e para com a terra, que também estão pela hora da morte, resta acreditar que é possível uma reorganização das vontades mediante a vida comunitária e COMUNicação.

\section{Uma análise possível na Região Oeste de Santa Catarina}

A dinâmica socioeconômica que se estabeleceu com a colonização na região Oeste de Santa Catarina, por volta do início do século XX, caracterizou-se pela predominância da família como unidade organizadora do processo produtivo e do trabalho. Neste modelo, predomina a propriedade direta dos instrumentos de trabalho por parte de quem trabalha. O que se obtém é fruto da jornada de trabalho gratuito da família, que executa praticamente todas as operações relativas à produção (seleção de sementes, plantio, colheita, estocagem, transporte...). Fatores como a falta de mercado, famílias numerosas, meios de transportes e comunicações rudimentares, terras montanhosas, além do transplante do modelo de propriedade das regiões de origem, fizeram com que se pautasse a colonização sobre a propriedade familiar e da produção de subsistência.

Os recursos naturais da região viabilizaram um modelo de desenvolvimento econômico de reduzida orientação para o mercado. A existência de mata nativa e a boa fertilidade natural do solo propiciaram ao migrante uma relativa autonomia e autossuficiência. A família, como unidade organizadora do processo produtivo, executava todas as operações relativas à produção: seleção de sementes, plantio, colheita, transporte, estocagem e escambo (esporadicamente, a venda). 
À medida que o espaço regional se tornou mais aberto e interdependente, as mudanças aconteceram de forma muito rápida. O desenvolvimento dos meios de comunicação, a interação com outros espaços, a preocupação do Estado e, ainda, o fascínio do capital (agroindústrias) pela região na qual pudesse espalhar seus interesses implantaram a denominada modernidade tecnológica. A interação cultural e econômica transformou o espaço engessado e fechado. A entrada mais agressiva do capitalismo destituiu o poder religioso e os laços de solidariedade que soldavam até então o tecido social.

A modernização, introduzida em toda a Região Oeste de Santa Catarina a partir da década de 1970, transformou o "espaço natural" e rompeu com a sociabilidade tradicional, integrando a região aos circuitos internacionais da economia. Para o governo brasileiro, era preciso que os diferentes espaços desconhecidos, bizarros e atrasados fossem incorporados ao projeto nacional da modernidade. Sobre o regionalismo naturalista da lentidão, do atraso e incivilidade, era preciso estender a pressa. Sendo assim, a modernidade, introduzida no espaço natural, tolheu iniciativas e jogou no esquecimento conhecimentos históricos, como a medicina natural, culinária, pequenos negócios (alambiques, fábricas, moinhos hidráulicos...), e redirecionou valores e concepções de mundo.

As grandes agroindústrias (leite, aves e suínos) colocam-se como centrais irradiadoras da modernidade da região e implantam relações artificiais no campo. As empresas hegemônicas, além da modernização das atividades agrícolas, redirecionaram drasticamente a forma de vida de suas populações. Agem sobre uma parcela do território e governam por metas. As metas e os prêmios contagiam, classificam, excluem, humilham e criam o espetáculo da denúncia. A competitividade destroçou antigas solidariedades horizontais e implantou a verticalidade. "Nexos verticais se superpõem à compartimentação horizontal, característica da história humana até data recente.” (SANTOS, 2001, p. 84). Essas empresas, a partir do seu epicentro de atuação, mudam as formas de ser e de agir. Quebram resistências, fidelidades, sequestram autonomias, potencializam vocações e impõem velocidades.

Os filhos dos antigos camponeses são agora operários das agroindústrias, onde são, igualmente, enquadrados. No espaço fechado e recortado da empresa, o poder é exercido pela coerção. Os dispositivos disciplinares vão desde a ameaça de demissão à 
cobrança dos que o circundam. "A pirâmide disciplinar constitui

a pequena célula do poder no interior da qual a separação, a coordenação e o controle das tarefas foram impostas e tornaramse eficazes." (FOUCAULT, 1992, p. 173-174). Desta forma, a rede assimétrica de poderes sustenta um poder central (chefe da empresa), que, por sua vez, mantém a multidão de operários compactados e vigiados. O senso de honra alimentado pelo operário, aliado à vergonha e ao embaraço, o tornam um ser altamente disciplinado e previsível.

O operário, posto ao ritmo da máquina, é forçado a uma disciplina de trabalho. A partir de Foucault (1992), é possível traçar um Diagrama Disciplinar que cabe no debate anterior; existe, para os operários, um mecanismo de organização do espaço (perfilação), controle do tempo (produção máxima no mínimo de tempo), vigilância (observação de um pelo outro e, consequentemente, de todos por todos) e, por fim, o registro contínuo do conhecimento (que se constitui num mapeamento completo de cada um e de suas potencialidades).

Aos colonos remanescentes e agora denominados de granjeiros, resta a obediência às regras da racionalidade e a adaptação ao mercado global. Enfim, no espaço rural, introduziuse um processo de produção que cumpre a estrita obediência aos mandamentos científicos e técnicos, enquanto no espaço urbano a hegemonia das empresas estabelece suas relações.

A submissão às novas regras da economia desarticula identidades e cria novas, submetendo as pessoas, o seu trabalho, a sua vida social, religiosa e a sua cultura, aos interesses restritos do mercado.

\section{Considerações finais}

Nos últimos 70 anos, observam-se profundas transformações no mundo. Procuramos nesse texto, explicar essas transformações através da metáfora da neopangeia, que significa o mundo inteiro unificado, mas, dessa vez, pelos cabos, sinais e técnicas. As mudanças se avolumam devido ao mercado cada vez mais avassalador e insensível que imprime nos corpos dos indivíduos contemporâneos a vontade e o desejo do consumo.

O consumo dos novos tempos tem como característica fundamental o descarte. Descarte esse que está alicerçado na ideia de obsolescência programada. Devido à velocidade de 
produção e à velocidade de lançamentos, o mercado tem de criar em seus consumidores o desejo de consumir, mas ao mesmo tempo de descartar, somado à velocidade dos acontecimentos e da virtualidade das relações, não somente em termos de comunidades virtuais, mas da efemeridade mesma das relações tête-à-tête. Logo, desejos de consumo e de descarte, juntamente com a vontade de diferenciação, tornam o mundo num aglomerado de diferentesiguais levando o homem à deriva da mensagem do consumo e do desejo.

Analisamos o processo global de consumo e ao mesmo tempo nos voltamos para sociedades em que o processo de dispersão do desejo e da compra está sendo plantado nos corações de homens, mulheres e jovens. Especificamente na Região Oeste de Santa Catarina, a modernidade criou um abismo entre o presente e o passado. Em toda a região, idiomas estão sendo extintos; fidelidades, negligenciadas; a medicina natural, completamente solapada; e experiências camponesas, ridicularizadas. As gerações mais velhas perderam o poder e estão sendo substituídos por gerações da obsolescência, da contingência, da habitação de mundo e do outro.

\section{Referências}

BAUMAN, Zygmunt. Capitalismo parasitário. Rio de Janeiro: Zahar, 2010.

BIRMAN, Joel. Mal-estar na atualidade: a psicanálise e as novas formas de subjetivação. Rio de Janeiro: Civilização Brasileira, 1999.

COSTA, Arthur Ferreira. O Oeste Catarinense: visões e sugestões de um excursionista. Rio de Janeiro: Villas Boas \& Cia, 1929.

FARIA, A. Nogueira de. Poder e Domínio. Rio de Janeiro: EDC, 1991.

FOUCAULT, Michel. A Microfísica do poder. 10. ed. Rio de Janeiro: Graal, 1992.

GASSET, José Ortega y. A Rebelião das Massas. São Paulo: Martins Fontes, 2002.

KREUTZ, Lúcio. O professor paroquial. Porto Alegre: UFRGS, 1990.

IANNI, Octávio. A era do globalismo. 9. ed. Rio de Janeiro: Civilização Brasileira, 2007. 
LINDO, Augusto Pérez. Era das mutações: cenários e filosofias de mudanças no mundo. São Paulo: UNIMEP, 2000.

MARX, Karl. Manifesto comunista. Rio de Janeiro: Paz e Terra, 2009. MORAES, Dênis de. Globalização Mídia e Cultura Contemporânea: a dialética das mídias globais. Campo Grande: Letra Livre, 1997.

MORIN, Edgar. Cultura de massa no século XX: Espírito do tempo 1 - Neurose. Rio de Janeiro: Forense Universitária, 2005.

NIETZSCHE, Friedrich. Para Além do Bem e do Mal: prelúdio a uma Filosofia do Futuro. São Paulo: Martin Claret, 2007.

RENK, Arlene. Narrativas da Diferença. Chapecó, SC: Argos, 2004.

SANTOS, Milton. Por uma outra globalização. Rio de Janeiro: Record, 2001.

WERLANG, Alceu Antonio. A Disputa e ocupação do espaço no oeste catarinense. Chapecó, SC: Argos, 2006.

\title{
MASS CONSUMPTION: THE PLANNED OBSOLESCENCE INTHE CONTEMPORARY SOCIETY
}

\begin{abstract}
This article is aimed at understanding the societal transformations derived from the consumer society. As the world is assembled by the technological advances, the homogenization of culture based on mass consumption and the processes of vertical integration from those who consume and those who can not but want to consume. In a second stage had as purpose to analyze the different consumption patterns experienced in the Far West of Santa Catarina from the I half of the twentieth century. This is an analysis from the deployment of private property in the region by European descendants. The region has adapted to two distinct periods: at the start had few external parameters, in view of its isolation by the lack of means of communication and transport, this period lasted until around the 1970s, and post-70 when major agricultural industries (dairy, poultry and pork) has put himself as the modern center for the region, ruling according to their market rules.
\end{abstract}

Keywords: Subsistence. Consumer society. Globalization. 
